\title{
SORPTION POTENTIAL OF TREATED PLANT RESIDUES VIZ. POTATO PEEL AND NEEM BARK FOR REMOVAL OF SYNTHETIC DYES FROM AQUEOUS SOLUTION
}

\author{
Neetu Sharma ${ }^{1, *}$, D. P. Tiwari ${ }^{2}$ and S. K. Singh ${ }^{3}$ \\ ${ }^{1}$ Department of Environmental Studies, SSN College, Alipur, Delhi (110036), India \\ ${ }^{2}$ Department of Chemical Engineering, DCRUST, Murthal, Sonepat (131039), India, \\ ${ }^{3}$ Department of Environmental Engineering, DTU, Delhi (110042), India, \\ *E-mail: sharma.neetu80@gmail.com
}

\begin{abstract}
The present study aims to identify the suitable low-cost adsorbent obtained from plant residues viz. potato peel and neem bark. Sorption potential of chemically treated potato peel and neem bark is observed on three different synthetic dyes viz. Methylene Blue (MB), Malachite Green (MG) and Direct Red 81 (DR-81). Selected adsorbents are treated with formaldehyde and sulphuric acid solution separately and consequently four different adsorbents PP and APP, NB and ANB are obtained. The monolayer adsorption capacity of HCHO treated potato peel (PP) for MB, MG, and DR81 is estimated as $47.6 \mathrm{mg} / \mathrm{gm}, 125 \mathrm{mg} / \mathrm{gm}$ and $58.8 \mathrm{mg} / \mathrm{gm}$ respectively whereas the monolayer adsorption capacity of HCHO treated neem bark (NB) is obtained as $90.9 \mathrm{mg} / \mathrm{gm}, 250 \mathrm{mg} / \mathrm{gm}$ and $8.40 \mathrm{mg} / \mathrm{gm}$ for the same dyes. In case of acid-treated potato peel (APP) the monolayer adsorption capacity for MB, MG and DR-81 are estimated as $41.6 \mathrm{mg} / \mathrm{gm}, 166 \mathrm{mg} / \mathrm{gm}$ and $10.41 \mathrm{mg} / \mathrm{gm}$ respectively whereas the adsorption capacity of acid-treated neem bark (ANB) for the same dyes is obtained as $1000 \mathrm{mg} / \mathrm{gm}, 500 \mathrm{mg} / \mathrm{gm}$ and $5.71 \mathrm{mg} / \mathrm{gm}$ respectively. From the study it was found that NB and ANB performed better than PP and APP for basic dyes, Methylene Blue and Malachite Green whereas for removal of acidic dye, Direct Red 81, formaldehyde-treated potato peel (PP) emerged out as the superior adsorbent. Also, ANB worked remarkably for cationic dyes while PP worked efficiently for anionic dye.

Keywords: Formaldehyde treated Potato Peel (PP), Formaldehyde-treated Neem Bark (NB), Sulphuric Acid-treated Potato Peel (APP), Sulphuric Acid-treated Neem Bark (ANB), Synthetic Dyes, Sorption Potential.
\end{abstract}

(C) RASĀYAN. All rights reserved

\section{INTRODUCTION}

Extensive use of dyes and unproductive dying processes in textile industries are significantly affecting our aquatic regime. Wastewater from the dying industry includes moderate concentration (10-200 $\mathrm{mg}^{\left.-\mathrm{ml}^{-1}\right)}$ of dyestuffs which significantly affect the aquatic ecosystems. ${ }^{1}$ Dying industries are facing a major problem in removing synthetic dyes from wastewater globally. Synthetic dyes are hazardous due to the presence of harmful persistent and toxic substances. These persistent compounds are non-biodegradable and get accumulates further throughout the food chain leaving severe toxic and carcinogenic effects on flora and fauna. $^{2}$ Numerous physicochemical techniques such as coagulation, ${ }^{3}$ ultra-filtration, ${ }^{4}$ electrochemical processes, ${ }^{5}$ nano-filtration, ${ }^{6}$ photo-oxidation, ${ }^{7}$ advance oxidation process ${ }^{8}$ Reverse Osmosis, ${ }^{9}$ ozonation, ${ }^{10}$ liquid-liquid extraction, ${ }^{11}$ supported liquid membrane ${ }^{12}$ and adsorption ${ }^{13}$ on commercial activated carbon are used in past for removal of dyes. Among them the adsorption method is well accepted and considered as an efficient method for removing dyes from wastewater. Besides leaving little or no toxic pollutants, the adsorption process requires low initial capital and operating costs. ${ }^{14}$ The present study elucidates the sorption potential of chemically treated potato peel and neem bark on three synthetic dyes viz. Methylene Blue, Malachite Green and Direct Red 81. The first two dyes are common basic dyes while the third one is a direct dye used with acidic dyes in the textile industry. The selected adsorbents are treated with formaldehyde and sulphuric acid solution separately. The sorption potential of the adsorbents is studied broadly through a batch study by varying the parameters such as adsorbent dose, initial concentration, $\mathrm{pH}$ and change in temperature. The suitable mode and nature of the adsorption process are concluded by adsorption isotherms and chemical kinetics.

Rasayan J. Chem., 13(2), 1063-1073(2020)

http://dx.doi.org/10.31788/RJC.2020.1325405

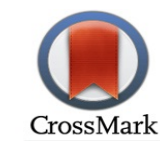


RASĀYAN J. Chem.

Vol. 13 | No. 2 |1063 - 1073| April - June | 2020

\section{Preparation of Sorbents}

\section{EXPERIMENTAL}

Potato peels obtained from the University canteen or mess and the neem bark pieces collected from the nearby locality are washed with water and air-dried in an oven at $70^{\circ} \mathrm{C}$ for $24 \mathrm{hrs}$. After drying they are ground and reacted with formaldehyde and sulphuric acid solutions separately. The formaldehyde treatment helped in removing the natural color of raw adsorbents which could further delay the process of adsorption whereas acid treatment of adsorbents is done to achieve significant adsorption, the same as recorded by the acid-treated adsorbents in past. ${ }^{15-17}$

\section{Formaldehyde treatment}

The grinded potato peel mixture is dipped in $6 \% \mathrm{HCHO}$ overnight whereas the neem bark mixture is dipped in a solution of $37 \% \mathrm{HCHO} \& 0.2 \mathrm{~N} \mathrm{H}_{2} \mathrm{SO}_{4}$ overnight followed by soaking in $\mathrm{NaHCO}_{3}$ overnight to remove extra acid. Both of the treated adsorbents are further washed with distilled water until the decanted water becomes colorless and $\mathrm{pH}$ reached neutral. The adsorbents are then dried in an oven at $70^{\circ} \mathrm{C}$ and further sieved to obtain the particles of $80-150 \mu \mathrm{m}$ mesh size.

\section{Acid treatment}

Both the adsorbents are soaked in $36 \mathrm{~N} \mathrm{H}_{2} \mathrm{SO}_{4}$ separately and after leaving overnight they are further washed with distilled water until the $\mathrm{pH}$ reached neutral. After acid treatment, black colored powders of both the adsorbents are obtained. Both the adsorbents are dried in an oven at $105 \dot{c}$ and sieved through the mesh size of $80-150 \mu \mathrm{m}$. All the four types of adsorbents viz. formaldehyde-treated potato peel and neem bark ((PP and NB) or acid-treated potato peel and neem bark ((APP and ANB) are stored airtight in the bottle.

\section{Sorbets selected}

Methylene Blue (MB), Malachite Green (MG) and Direct Red 81 (DR 81) dyes are selected as sorbet. The first two dyes are common basic dyes while the third one is a direct dye that is used with acidic dyes in textile industries.

\section{Analytical Procedure}

For the analytical procedure, $1000 \mathrm{ppm}$ of stock solution of all the three dyes is prepared. A comparative study of removal of dye on all the four adsorbents is studied by considering various parameters like adsorbent dose, the concentration of dye, $\mathrm{pH}$ of the solution, and change in temperature. Experiments are performed in batches at room temperature by shaking a definite volume $(50-100 \mathrm{ml})$ of specific dye concentration (10-250 ppm) with a precise amount of dose (0.1gm-1.0 gm) of each adsorbent taken in 200 $\mathrm{ml}$ of Erlenmeyer conical flask at the speed of $125 \mathrm{rpm}$. For determining the concentration of dye, Lambert Beer's method is used by using the Chemito UV-Visible Spectrophotometer having the wavelength range of $190-1100 \mathrm{~nm}$ and bandwidth of 1.6/1.0 nm. Standard concentrations of dyes (1-10 ppm) are prepared to obtain the respective calibration curves and the graph factor is calculated which is further used to assess the removal efficiency with minimum error. All the samples are examined on the recorded $\lambda_{\max }$ of $662 \mathrm{~nm}$ for Methylene Blue (MB), $612 \mathrm{~nm}$ for Malachite Green (MG) and $520 \mathrm{~nm}$ for Direct Red-81 (DR-81). Sorption of dye on various adsorbents and percentage removal of dye is calculated by the mass balance equation as given below where q denotes the amount of dye adsorbed on the adsorbent $(\mathrm{mg} / \mathrm{gm})$; $\mathrm{V}$ denotes the volume of the solution (l), $\mathrm{m}$ denotes the amount of adsorbent taken in $\mathrm{gm} ; \mathrm{C}_{\mathrm{i}}$ and $\mathrm{Cf}$ denotes the dye concentration in $\mathrm{mg} / \mathrm{l}$ before and after adsorption respectively.

$$
\mathrm{q}=\frac{C_{i}-C_{f}}{m} \times V
$$

Whereas percentage removal of dye is calculated by the given formula:

$$
\% \text { Removal }=\frac{C_{i}-C_{f}}{C_{i}} \times 100
$$


RASĀYAN J. Chem.

Vol. 13 | No. 2 |1063 - 1073| April - June | 2020

\section{Experimental Validation}

For knowing the mode and nature of adsorption three isotherm models viz Langmuir, Freundlich and Temkin are fitted to study. Equilibrium experiments are carried out by adding a fixed amount of adsorbent dose $(0.25 \mathrm{~g})$ containing a definite volume (100 $\mathrm{ml}$ in each case) of different initial concentrations (10-250 $\mathrm{ppm}$ ) of dyes without changing $\mathrm{pH}$. The linear form of Langmuir, empirical equation of Freundlich and Temkin isotherm models are respectively explained by the following expressions:

$$
\begin{aligned}
& \frac{C e}{q e}=\frac{1}{Q_{0} b}+\frac{C e}{Q_{0}} \\
& \log q_{e}=\mathrm{LogK}_{\mathrm{F}}+\frac{1}{n} \log C_{e} \\
& q_{e}=\mathrm{B} \ln \mathrm{A}+\mathrm{B} \ln C_{e}
\end{aligned}
$$

Here, in Langmuir's equation, Ce is the equilibrium concentration $(\mathrm{mg} / \mathrm{l})$; qe is the amount of dye adsorbed at equilibrium $(\mathrm{mg} / \mathrm{g}) ; \mathrm{Q}_{0}$ is the maximum dye per gram of adsorbent $(\mathrm{mg} / \mathrm{g})$ and $\mathrm{b}$ is Langmuir constant related to the energy of adsorption $(1 / \mathrm{mg})$. In Freudlich's equation, $\mathrm{K}_{\mathrm{F}}$ is a constant related to sorption capacity. $1 / \mathrm{n}$ is an empirical parameter related to the sorption intensity of the adsorbent. In Temkin's equation, A is Temkin's constant representing sorbet - sorbent interactions and B is another constant related to the heat of adsorption. The kinetic plots of Lagergen first order and pseudo-second-order are made at the initial concentration of $100 \mathrm{ppm}$ for all the four adsorbents. Pseudo-first order and pseudo-second-order kinetic models are used to describe the kinetics of adsorption. The integrated form of Lagergen first-order kinetic model is represented by the equation given below:

$$
\log \left(q_{e^{-}} q t\right)=\log q_{e^{-}}\left(k_{1} / 2.303\right) t
$$

Here $\mathrm{k}_{1}$ is the rate constant of first-order adsorption $(1 / \mathrm{min})$; $\mathrm{q}_{\mathrm{e}}$ is the amount of dye adsorbed in $\mathrm{mg} / \mathrm{g}$ at equilibrium and $\mathrm{q}_{\mathrm{t}}$ is the amount of dye adsorbed in $\mathrm{mg} / \mathrm{g}$ at any time $\mathrm{t}$. The linear form of the pseudosecond-order kinetic model rate equation is expressed as:

$t / q t=1 / K_{2} q_{e}{ }^{2}+\left(1 / q_{e}\right) t$

Here $\mathrm{k}_{2}$ is the rate constant of second-order adsorption $(1 / \mathrm{min})$ depends on the sorption capacity of the solid phase. The initial sorption rate, $\mathrm{h}(\mathrm{mg} / \mathrm{g} . \mathrm{min})$ is also calculated with the help of the second-order kinetic model by the following expression:

$h=k_{2} q_{e}^{2}$

The removal efficiency of the adsorbents is measured at three different temperatures i.e. $25^{\circ} \mathrm{C}, 35^{\circ} \mathrm{C}$ and $45^{\circ} \mathrm{C}$ for calculating the thermodynamic parameters. The thermodynamic parameters of the adsorption, i.e. the standard Gibbs free energy $\left(\Delta G^{\circ}\right)$, enthalpy $\left(\Delta H^{\circ}\right)$ and entropy $\left(\Delta S^{\circ}\right)$, are calculated from the Van't Hoff equation:

$$
\Delta G^{\circ}=-R T \ln K_{\mathrm{d}}
$$

The value of $K_{\mathrm{d}}$ is determined from the Freundlich constants $\mathrm{K}_{\mathrm{f}}$ and $\mathrm{n}$ by using the formula as mentioned in literature. $^{18}$

$K_{d}=K f^{n}$

The slope and the intercept of the plots of $\ln K_{\mathrm{d}}$ versus $1 / T$ are used to determine the $\Delta H^{\circ}$ and $\Delta S^{\circ}$ values:

$$
\ln K_{\mathrm{d}}=\frac{\Delta S}{R}-\frac{\Delta H}{R T}
$$

\section{Physiochemical Characteristics of the Adsorbents \\ SEM and FTIR Analysis}

SEM images of all four adsorbents showed significant particle and pore size for the dye to be adsorbed as already mentioned in earlier publication. ${ }^{19}$ From the study it is determined that PP reflected the presence of 
RASĀYAN J. Chem.

Vol. 13 | No. 2 |1063 - 1073| April - June | 2020

smooth particles of size $22 \mu \mathrm{m}-30 \mu \mathrm{m}$ while NB showed roughly shaped particles of average size from $8.38 \mu \mathrm{m}$ to $10.6 \mu \mathrm{m}$. Moreover, the APP and ANB showed a charged and smooth surface area. The comparative chart of FTIR spectra mentioned in previous publication ${ }^{19}$ also declared that all the four adsorbents represented relatively similar characteristic adsorption spectra. It is well defined from the study that all the four adsorbents contained carboxylic group $\left(1500-1640 \mathrm{~cm}^{-1}\right)$, phenolic $\left(3400-3300 \mathrm{~cm}^{-1}\right)$, amines (1200-1025 $\left.\mathrm{cm}^{-1}\right)$ and sulphoxides group $\left(\sim 1050 \mathrm{~cm}^{-1}\right)$ whereas some groups like $\mathrm{C}-\mathrm{H}, \mathrm{C}=\mathrm{C}$ and $\mathrm{C}-\mathrm{N}(2950-$ $2800,1690-1630,1200-1025 \mathrm{~cm}^{-1}$ ) stretch got invisible after sulphuric acid treatment.

\section{Effect of Dose, Concentration, $\mathrm{pH}$ and Temperature on the Removal of Dye}

With the increase in dose, the percentage removal of PP, NB \& APP for sorption of MB dye increases from $75 \%$ to $93 \%, 92 \%$ to $96 \%$ and $75 \%$ to $100 \%$ respectively whereas the percentage removal of ANB decreases with increase in dose. The percentage removal of all the four adsorbents for sorption of MG and DR 81 dye also increases with increase in dose. Increase in adsorption might be due to the presence of more surface area on the adsorbents while a decrease in percentage removal might be due to the overloading of the adsorbent. ${ }^{15,20}$ Figure-1(i, ii, iii) represents the effect of adsorbent dose of different adsorbents for removing $\mathrm{MB}, \mathrm{MG}$ and $\mathrm{DR}-81$ respectively.
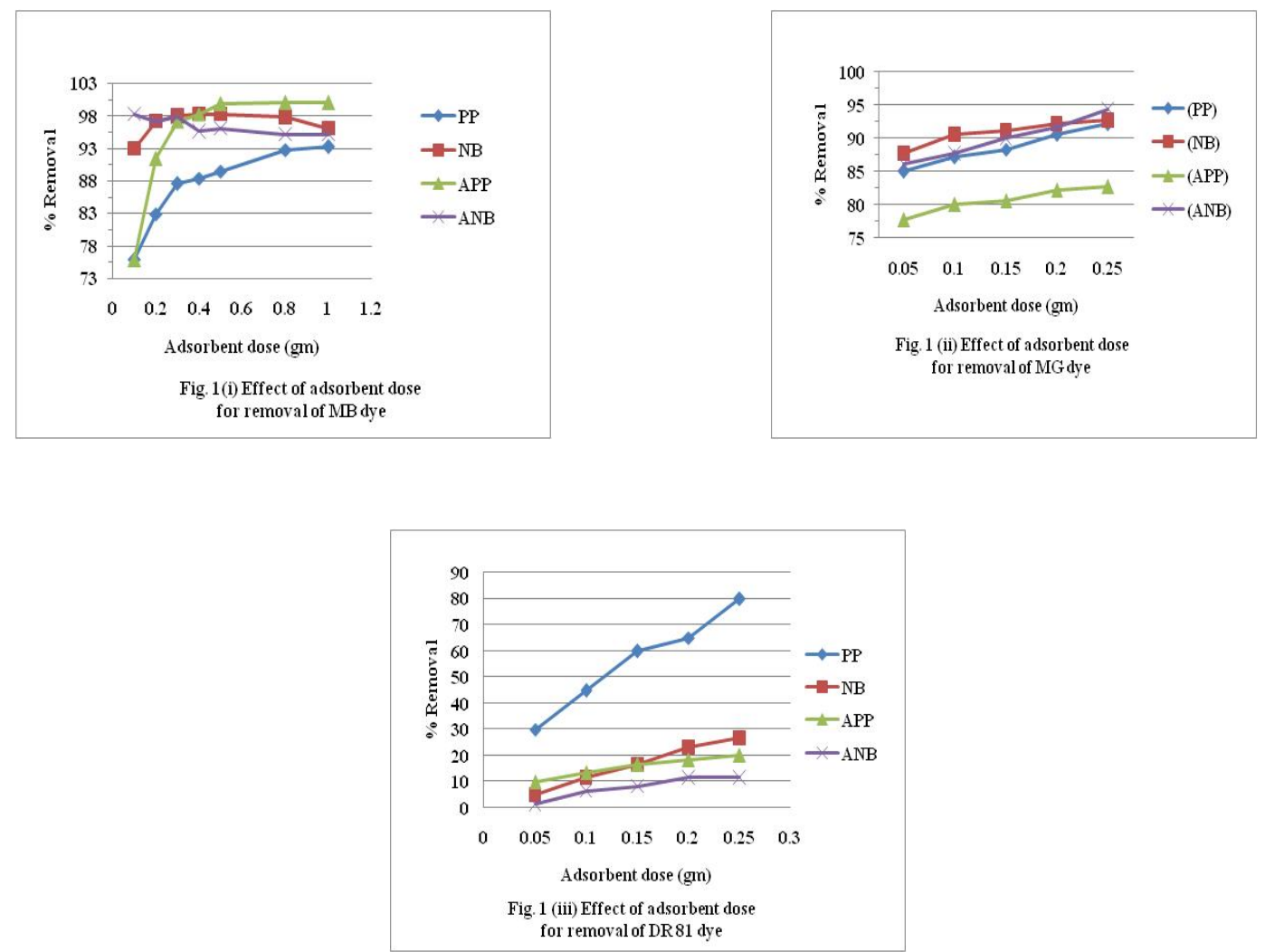

Fig.-1

On varying concentration, On varying concentration, the percentage removal of MB dye in case of PP, APP and NB decreases significantly from $85 \%$ to $63 \%, 100 \%$ to $62 \%$ and $92 \%$ to $85 \%$ respectively whereas increase in removal seen in ANB from $90 \%$ to $97 \%$ respectively. The excellent performance of both formaldehyde-treated adsorbents for removal of MG dye measured at low concentrations while the same is estimated for acid-treated adsorbents at higher concentrations. The decrease in removal might be attributed due to the saturation of sorption sites on the adsorbent as the concentration of dye increases. ${ }^{21-22}$ For removal of DR 81 dye, both formaldehyde-treated adsorbents performed well at high concentrations while the same is estimated for acid-treated adsorbents at lower concentrations. ${ }^{15}$ The increase in removal efficiency by an increase in concentration might be due to the presence of more surface area on the adsorbents. ${ }^{23}$ The initial concentration in solution played an important role to overcome mass transfer resistance of sorbet between 
RASĀYAN J. Chem.

Vol. 13 | No. 2 |1063 - 1073| April - June | 2020

aqueous and solid phases. Figure-2 (i, ii, iii) depicts the effect of change in concentration for removal of all the three dyes MB, MG and DR 81 respectively.
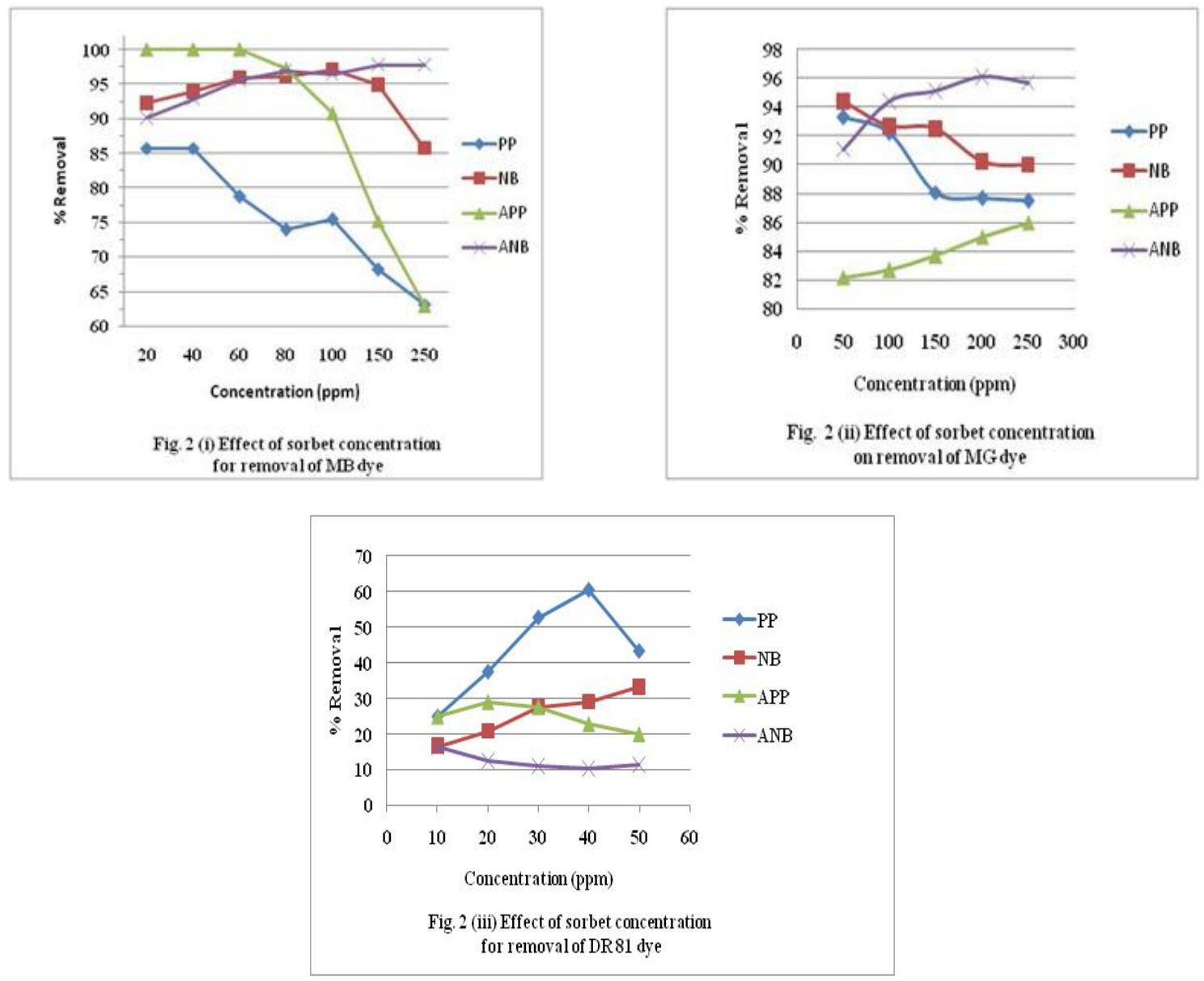

Fig.-2

For removal of MB and MG dye, PP and APP worked effectively in alkaline condition whereas NB and ANB worked remarkably in acidic environment. Increase in negative charged ions on PP and APP favoured the adsorption of cationic dyes in alkaline condition. It might be due to pectin present on the surface of adsorbents. ${ }^{25}$ Maximum removal of cationic dye on NB and ANB in acidic medium might be due presence of cellulosic compounds (carboxylic and phenolic groups) present on the surface of the sorbent. ${ }^{26}$ For the removal of DR 81 dye, all the adsorbents performed substantially in an acidic environment. At high $\mathrm{pH}$, the low adsorption capacity was measured due to resistance between hydroxyl ions and negative charge of dye ions on the sorption sites. ${ }^{27}$ The acidic medium favored the adsorption of anionic dye due to the presence of cellulosic compounds (carboxylic and phenolic groups) on the sorbent surface. ${ }^{26}$ Figure-3(i, ii, iii) represents the effect of change in $\mathrm{pH}$ for removal of MB, MG and DR 81 dye respectively.

With an increase in temperature the adsorption capacity of all the four adsorbents for removal of all three dyes $\mathrm{MB}, \mathrm{MG}$ and $\mathrm{DR} 81$ decreases initially and then increases by the increase in temperature further. It might be due to the weakening of adsorptive forces in case of the exothermic process whereas the affinity of adsorption increases with the rise in temperature might be due to large interaction of dye molecule with the functional groups present at the sorbent surface for the endothermic reactions. ${ }^{28}$ The increase in adsorption capacity at higher temperatures might be due to the enlargement of pore size and activation of the adsorbent surface ${ }^{29}$. All the adsorbents showed good removal at room temperature as shown in Fig.-4(i,ii,iii). 
RASĀYAN J. Chem.

Vol. 13 | No. 2 |1063 - 1073| April - June | 2020
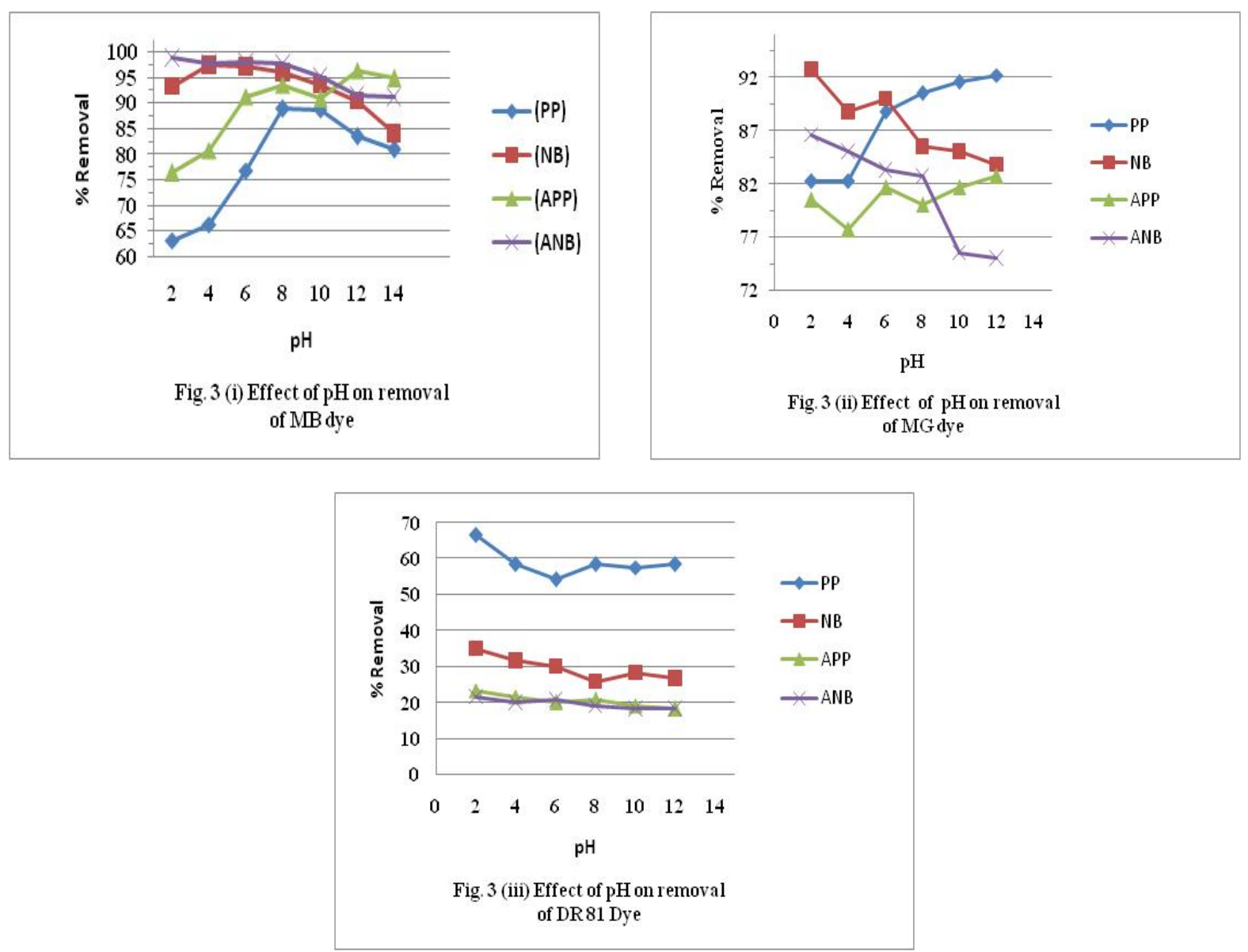

Fig.-3

\section{Equilibrium Study}

It is well represented from Table-1 that both Freundlich and Temkin isotherms models are a best suited model for adsorption of MG and DR 81 dyes whereas, for adsorption of MB dye, PP and APP responded good behavior with Langmuir isotherm and NB and ANB fitted quite well with Temkin isotherm model. The Langmuir model described the monolayer sorption nature of PP and APP Whereas Temkin isotherm model reflected the chemical adsorption behavior. The chemisorptions behavior might be due to the acquisition of more energetic adsorption sites initially. ${ }^{30}$ The unbiased behavior of the adsorbents with all the three models established that adsorbents favored monolayer adsorption initially followed by chemisorptions. The heterogenous behavior of adsorbents might be due to that, the natural agricultural adsorbents have a rough surface which facilitates the heterogeneous adsorption due to energetically nonequivalent adsorption sites. ${ }^{31}$

The maximum monolayer adsorption capacity of PP and APP for adsorption of MB is recovered as 47.62 and $41.60 \mathrm{mg} / \mathrm{gm}$ respectively whereas the maximum adsorption capacity of NB and ANB for the uptake of methylene blue is determined as $90.91 \mathrm{mg} / \mathrm{gm}$ and $1000 \mathrm{mg} / \mathrm{gm}$ respectively which are higher than the efficiency measured for $\mathrm{MB}$ on cherry sawdust, Oak sawdust and pitch pine sawdust reported by $\mathrm{F}$. Ferrero. ${ }^{26}$ The $\mathrm{Q}_{0}$ determined for PP and APP adsorbents for removal of MG is measured as 125 and 111 $\mathrm{mg} / \mathrm{gm}$ whereas the maximum sorption potential of NB and ANB is obtained as 166 and $500 \mathrm{mg} / \mathrm{gm}$. The $\mathrm{Q}_{0}$ determined for all the four adsorbents are higher than the value of $9.7 \mathrm{mg} / \mathrm{gm}$ and $63.8 \mathrm{mg} / \mathrm{gm}$ obtained by Hema and Arivoli and Y.C. Sharma et al respectively for malachite green removal on activated carbon of dried leaves of Pandanus and rice husk respectively. ${ }^{32-33}$

The maximum amount of DR 81 dye adsorbed per gram of the adsorbent $\left(\mathrm{Q}_{0}\right)$ estimated for PP and APP is higher than NB and ANB. The $\mathrm{Q}_{0}$ values are obtained in the order of $\mathrm{PP}>\mathrm{APP}>\mathrm{NB}>\mathrm{ANB}$ with values 58.8, 
RASĀYAN J. Chem.

Vol. 13 | No. 2 |1063 - 1073| April - June | 2020

$10.41,8.40$ and $5.71 \mathrm{mg} / \mathrm{gm}$ respectively. The performance potential of PP with $58.8 \mathrm{mg} / \mathrm{gm}$ is higher than the value of $6.43 \mathrm{mg} / \mathrm{gm}$ and $10 \mathrm{mg} / \mathrm{gm}$ obtained by Heravi 2012 and Khan 2012 for the removal of same dye DR 81 on Chamomilla plant and Bamboo sawdust respectively. ${ }^{34-35}$ The column study accomplished by taking the same adsorbents for removal of DR 81 also proved that PP worked remarkably than the other three adsorbents. ${ }^{36}$ The value of $\mathrm{n}$ is greater than one for all the four adsorbents as shown in Table-1 states that the nature of adsorption is favorable.
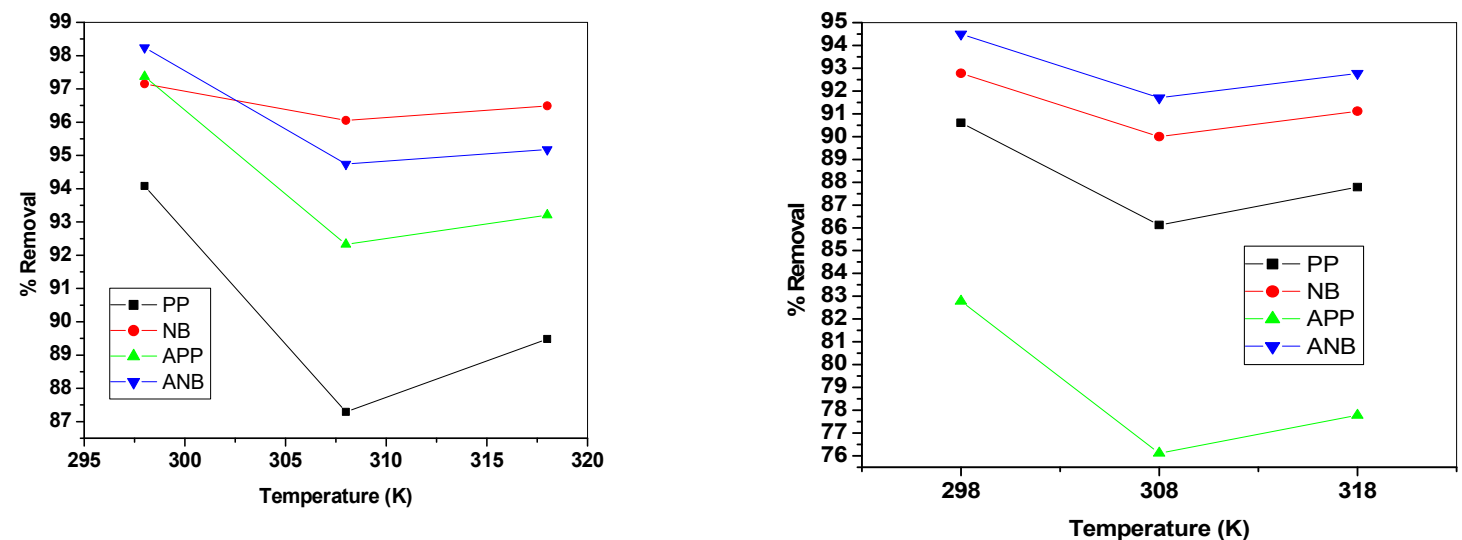

Fig.-4 (i) Effect of Change in Temperature on Removal of MB Fig.-4 (ii) Effect of Change in Temperature on Removal of MG

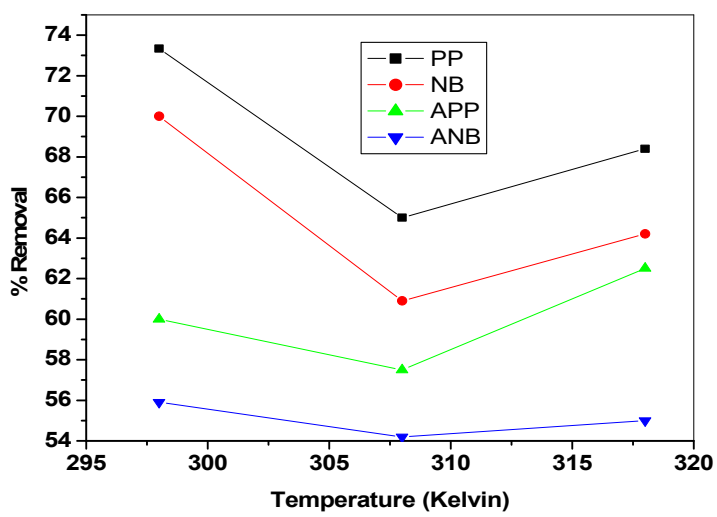

Fig.-4 (iii) Effect of Change in Temperature on Removal of DR 81 dye

Table-1: Adsorption Isotherms parameters of Different Adsorbents Studied for Removal of MB, MG and DR 81Dyes

\begin{tabular}{|c|c|c|c|c|c|c|c|c|c|}
\hline $\begin{array}{l}\text { Isotherm } \\
\text { Models } \rightarrow\end{array}$ & \multicolumn{3}{|c|}{ Langmuir's Isotherm Model } & \multicolumn{3}{|c|}{$\begin{array}{l}\text { Freudlich's Isotherm } \\
\text { Model }\end{array}$} & \multicolumn{3}{|c|}{$\begin{array}{l}\text { Temkin's Isotherm } \\
\text { Model }\end{array}$} \\
\hline Adsorbents $\downarrow$ & $\mathrm{K}_{\mathrm{L}}(\mathrm{b})$ & $\mathrm{Q}_{0}$ & $\mathrm{R}^{2}$ & $\mathrm{~K}_{\mathrm{F}}$ & $\mathrm{N}$ & $\mathrm{R}^{2}$ & $\mathrm{~B}$ & $\mathrm{~A}$ & $\mathrm{R}^{2}$ \\
\hline PP Vs MB & 0.03 & 47.62 & 0.99 & 1.87 & 1.46 & 0.95 & 8.89 & 0.39 & 0.98 \\
\hline NB Vs MB & 0.03 & 90.91 & 0.21 & 3.63 & 1.35 & 0.56 & 0.06 & 43477 & 0.85 \\
\hline APP Vs MB & 0.107 & 41.60 & 0.96 & 7.46 & 2.80 & 0.64 & 0.116 & 0.056 & 0.86 \\
\hline ANB Vs MB & 0.006 & 1000.0 & 0.005 & 6.51 & 1.10 & 0.84 & 19.60 & 1.35 & 0.99 \\
\hline PP Vs MG & 0.06 & 125 & 0.89 & 12.07 & 1.78 & 0.99 & 24.19 & 0.80 & 0.91 \\
\hline NB Vs MG & 0.1 & 166 & 0.884 & 18.23 & 1.5 & 0.88 & 0.023 & $2.67 \times 10^{-36}$ & 0.95 \\
\hline APP Vs MG & 0.05 & 111 & 0.86 & 3.5 & 0.98 & 0.97 & 23.7 & 0.65 & 0.87 \\
\hline ANB Vs MG & 0.017 & 500 & 0.407 & 9.4 & 1.14 & 0.97 & 40.07 & 0.62 & 0.91 \\
\hline PP Vs DR 81 & 24.3 & 58.8 & 0.71 & 0.40 & 1.09 & 0.99 & 4.89 & 0.001 & 0.80 \\
\hline NB Vs DR 81 & 0.021 & 8.40 & 0.31 & 0.15 & 0.93 & 0.90 & 3.55 & 0.174 & 0.70 \\
\hline APP Vs DR 81 & 0.017 & 10.41 & 0.62 & 0.224 & 1.22 & 0.92 & 1.80 & 0.24 & 0.98 \\
\hline ANB Vs DR 81 & 0.012 & 5.71 & 0.59 & 0.117 & 1.32 & 0.97 & 0.90 & $1.03 \times 10^{-7}$ & 0.86 \\
\hline
\end{tabular}


RASĀYAN J. Chem.

Vol. 13 | No. 2 |1063 - 1073| April - June | 2020

\section{Chemical Kinetics}

From Table-2 it is well seen that the second-order kinetic model fitted quite well with the observed data of all the four adsorbents. The calculated values of $\mathrm{q}_{\mathrm{e}}$ for all the four adsorbents from the second-order kinetic equation are finely comparable with the experimental values of $\mathrm{q}_{\mathrm{e}}$. Similar results are reported by O"ktem ${ }^{37}$ and Srivastva ${ }^{38}$ for sorption of methylene blue on potato peel and neem bark respectively, by Srivastva ${ }^{39}$ for removal of malachite green on neem bark and mango bark and by Heravi and $\mathrm{Khan}^{34,35}$ for removal of DR 81 on Chamomilla plant and Bamboo sawdust respectively. The initial adsorption rate $h$ is higher in the case of both NB and ANB as compare to PP and APP for adsorption of MB. This suggested the high efficiency of these two adsorbents initially compare to PP and APP. Also, the chemical treatment of neem bark has increased the efficiency of adsorbents by increasing the surface properties like porosity and formation of more energetic sites which helps in attracting the dye molecule efficiently. The negatively charged auxochromes like hydroxyl, sulphonyl and the carboxylic group as distinguished from the FTIR study earlier, played a major role in attracting the cationic dye methylene blue.

Table-2: Kinetics Parameters of Different Adsorbents Studied for Removal of MB, MG and Dr 81 Dyes

\begin{tabular}{c|c|c|c|c|c|c|c|c|c}
\hline \multirow{2}{*}{ Adsorbents } & \multicolumn{3}{|c|}{ Pseudo First Order } & \multicolumn{3}{c|}{ Pseudo Second Order } & \multirow{2}{*}{$\mathrm{q}_{\mathrm{e}}(\exp )$} \\
\cline { 2 - 9 } & $\mathrm{q}_{\mathrm{e}}(\mathrm{cal})$ & $\mathrm{K}_{1}$ & $\mathrm{R}^{2}$ & $\mathrm{q}_{\mathrm{e}}(\mathrm{cal})$ & $\mathrm{K}_{2}$ & $\mathrm{R}^{2}$ & $\mathrm{~h}$ & \\
\hline PP Vs MB & 1.5 & 0.009 & 0.14 & 17.5 & 0.29 & 0.99 & 2.7 & 17.6 \\
\hline NB Vs MB & 0.71 & 0.016 & 0.29 & 19.2 & 0.016 & 0.99 & 22.1 & 19.2 \\
\hline APP Vs MB & 5.04 & 0.034 & 0.70 & 20.0 & 0.015 & 0.99 & 0.4 & 20.0 \\
\hline ANB Vs MB & 0.52 & 0.006 & 0.10 & 19.6 & 2.60 & 0.99 & 42.2 & 19.6 \\
\hline PP Vs MG & 1.12 & $9.2 \times 10^{-3}$ & 0.252 & 35.71 & 0.060 & 0.99 & 76.4 & 35.5 \\
\hline NB Vs MG & 1.64 & $2.3 \times 10^{-3}$ & 0.028 & 34.4 & 8.28 & 0.99 & 9.7 & 34.4 \\
\hline APP Vs MG & 3.89 & $1.0 \times 10^{-3}$ & 0.417 & 35.7 & 0.010 & 0.99 & 12.7 & 35.7 \\
\hline ANB Vs MG & 1.68 & $3.0 \times 10^{-3}$ & 0.77 & 37.0 & 0.365 & 0.99 & 499.6 & 37.0 \\
\hline PP Vs DR 81 & 3.96 & 0.032 & 0.65 & 10.75 & 0.009 & 0.96 & 1.04 & 9.3 \\
\hline NB Vs DR 81 & 3.60 & 0.016 & 0.35 & 7.35 & 0.019 & 0.90 & 1.02 & 8.0 \\
\hline APP Vs DR 81 & 1.83 & 0.016 & 0.74 & 3.48 & 0.081 & 0.95 & 0.98 & 4.0 \\
\hline ANB Vs DR 81 & 1.07 & 0.020 & 0.41 & 2.31 & 0.067 & 0.96 & 0.35 & 2.3 \\
\hline
\end{tabular}

The initial adsorption rate $\mathrm{h}$ calculated for adsorption of MG is higher in the case of PP and ANB as compare to NB and APP whereas the initial adsorption rate $h$ calculated for adsorption of DR 81 dye is higher in case of PP, NB and APP as compare to ANB. It reflected that the adsorbents with high $h$ values have good surface properties which helped in attracting the dye molecule.

\section{Thermodynamic Study}

As shown in Table-3, for adsorption of MB and MG dye, the $\Delta \mathrm{G}$ calculated is found to be negative which reflected the spontaneous nature of the adsorption process however the spontaneity decreases with increase in temperature whereas $\Delta \mathrm{G}$ measured for adsorption of DR 81dye is found to be positive which showed the non- spontaneous nature of the sorption process however the spontaneity increases with the increase in temperature.

According to Oepen et $a l^{40}{ }^{4}$ the amount of sorption free energy released decides the possibility of several kinds of interactions such as Van der Waals force is $4-10 \mathrm{~kJ} / \mathrm{mol}$, hydrophobic force is about $5 \mathrm{~kJ} / \mathrm{mol}$, the hydrogen bond is $2-40 \mathrm{~kJ} / \mathrm{mol}$, coordination exchange is $40 \mathrm{~kJ} / \mathrm{mol}$, dipole force is $2-29 \mathrm{~kJ} / \mathrm{mol}$, a chemical bond is above $60 \mathrm{~kJ} / \mathrm{mol}$. In the present study, the main interaction between the adsorbents and the dyes is probably the hydrogen bond and/or dipole force. The results based on sorption free energy ruled out the possibility of chemical bonding and suggested that the adsorption process is physiosorption in nature and mainly accomplished by the weak Van der Walls forces.

The negative values of $\Delta \mathrm{H}$ revealed that the sorption process is exothermic. Adsorption is invariably accomplished by a decrease in enthalpy and the heat evolved in range of $4-40 \mathrm{KJ} / \mathrm{mol}$ indicated physical 
RASĀYAN J. Chem.

Vol. 13 | No. 2 |1063 - 1073| April - June | 2020

adsorption mechanism while the heat evolved in range of 40-400 KJ/mol reflected the chemisorptions nature of the process. The high value of $\Delta \mathrm{H}$ in the case of sulphuric acid-treated potato peel and neem bark does not avoid the prospect of chemical bonding between the auxochromes (sulphonyl, carboxylic and hydroxyl group) and the dye molecule. The negative standard entropy suggested that there is a decrease in the degree of freedom.

Table-3: Thermodynamic Parameters Calculated from Van't Hoff Equation for Adsorption of MB, MG and DR 81 dye

\begin{tabular}{|c|c|c|c|c|c|c|c|c|}
\hline $\begin{array}{c}\mathrm{K}_{\mathrm{d}} \\
\text { Calculation } \\
\text { Method }\end{array}$ & Adsorbents & $\begin{array}{c}\text { Temperature } \\
(\mathrm{K})\end{array}$ & $\begin{array}{c}\text { Adsorbate } \\
\text { (Dye) }\end{array}$ & $\mathrm{Kd}$ & $\begin{array}{c}\Delta \mathrm{G} \\
(\mathrm{KJ} / \mathrm{mol})\end{array}$ & $\begin{array}{l}\text { Adsorbate } \\
\text { (Dye) }\end{array}$ & $\begin{array}{c}\Delta \mathrm{S} \\
(\mathrm{J} / \mathrm{mol} . \mathrm{k})\end{array}$ & $\begin{array}{c}\Delta \mathrm{H} \\
(\mathrm{KJ} / \mathrm{mol})\end{array}$ \\
\hline \multirow{12}{*}{$\mathrm{K}_{\mathrm{d}}=\mathrm{K}_{\mathrm{f}}^{\mathrm{n}}$} & PP & 278 & $\begin{array}{c}\text { MB } \\
\text { MG } \\
\text { DR 81 } \\
\end{array}$ & $\begin{array}{l}3.09 \\
84.2 \\
0.41 \\
\end{array}$ & $\begin{array}{c}-2.26 \\
-10.9 \\
2.20 \\
\end{array}$ & \multirow{3}{*}{$\begin{array}{c}\text { MB } \\
\text { MG } \\
\text { DR } 81\end{array}$} & \multirow{3}{*}{$\begin{array}{l}-17.35 \\
-377.0 \\
-99.18\end{array}$} & \multirow{3}{*}{$\begin{array}{c}-7.69 \\
-122.5 \\
-27.66\end{array}$} \\
\hline & PP & 308 & $\begin{array}{c}\text { MB } \\
\text { MG } \\
\text { DR } 81\end{array}$ & $\begin{array}{l}2.17 \\
6.67 \\
0.40\end{array}$ & $\begin{array}{c}-1.92 \\
-4.86 \\
2.32\end{array}$ & & & \\
\hline & PP & 318 & $\begin{array}{c}\text { MB } \\
\text { MG } \\
\text { DR } 81\end{array}$ & $\begin{array}{l}2.49 \\
3.84 \\
0.20\end{array}$ & $\begin{array}{l}-2.98 \\
-3.56 \\
4.22\end{array}$ & & & \\
\hline & NB & 278 & $\begin{array}{c}\text { MB } \\
\text { MG } \\
\text { DR } 81\end{array}$ & $\begin{array}{l}7.47 \\
77.8 \\
0.17\end{array}$ & $\begin{array}{l}-4.98 \\
-10.7 \\
4.37\end{array}$ & \multirow{3}{*}{$\begin{array}{c}\text { MB } \\
\text { MG } \\
\text { DR } 81\end{array}$} & \multirow{3}{*}{$\begin{array}{l}-75.5 \\
-11.5 \\
-35.11\end{array}$} & \multirow{3}{*}{$\begin{array}{c}-27.5 \\
-13.99 \\
-5.510\end{array}$} \\
\hline & NB & 308 & $\begin{array}{c}\text { MB } \\
\text { MG } \\
\text { DR } 81\end{array}$ & $\begin{array}{l}5.69 \\
50.9 \\
0.06\end{array}$ & $\begin{array}{c}-4.45 \\
-10.06 \\
6.84\end{array}$ & & & \\
\hline & NB & 318 & $\begin{array}{c}\text { MB } \\
\text { MG } \\
\text { DR } 81\end{array}$ & $\begin{array}{l}3.71 \\
84.5 \\
0.16\end{array}$ & $\begin{array}{l}-3.47 \\
-11.7 \\
4.84\end{array}$ & & & \\
\hline & APP & 278 & $\begin{array}{c}\text { MB } \\
\text { MG } \\
\text { DR } 81\end{array}$ & $\begin{array}{c}277.7 \\
5.15 \\
0.16\end{array}$ & $\begin{array}{c}-13.94 \\
-4.06 \\
4.52 \\
\end{array}$ & \multirow{3}{*}{$\begin{array}{c}\text { MB } \\
\text { MG } \\
\text { DR } 81\end{array}$} & \multirow{3}{*}{$\begin{array}{l}-494.8 \\
-140.0 \\
-25.28\end{array}$} & \multirow{3}{*}{$\begin{array}{l}-159.5 \\
-45.16 \\
-2.144\end{array}$} \\
\hline & APP & 308 & $\begin{array}{c}\text { MB } \\
\text { MG } \\
\text { DR } 81\end{array}$ & $\begin{array}{c}3.84 \\
1.10 \\
0.052\end{array}$ & $\begin{array}{c}-3.45 \\
-0.255 \\
7.54\end{array}$ & & & \\
\hline & APP & 318 & $\begin{array}{c}\text { MB } \\
\text { MG } \\
\text { DR } 81\end{array}$ & $\begin{array}{c}5.00 \\
1.67 \\
0.156\end{array}$ & $\begin{array}{c}-4.25 \\
-1.36 \\
4.89\end{array}$ & & & \\
\hline & ANB & 278 & $\begin{array}{c}\text { MB } \\
\text { MG } \\
\text { DR } 81\end{array}$ & $\begin{array}{c}7.85 \\
12.8 \\
0.058\end{array}$ & $\begin{array}{c}-5.10 \\
-6.32 \\
7.01\end{array}$ & \multirow{3}{*}{$\begin{array}{c}\text { MB } \\
\text { MG } \\
\text { DR } 81\end{array}$} & \multirow{3}{*}{$\begin{array}{c}19.9 \\
-14.04 \\
-89.95\end{array}$} & \multirow{3}{*}{$\begin{array}{l}-40.0 \\
-20.97 \\
-19.37\end{array}$} \\
\hline & ANB & 308 & $\begin{array}{c}\text { MB } \\
\text { MG } \\
\text { DR } 81\end{array}$ & $\begin{array}{c}2.20 \\
5.63 \\
0.027\end{array}$ & $\begin{array}{l}-2.0 \\
-4.42 \\
9.24\end{array}$ & & & \\
\hline & ANB & 318 & $\begin{array}{c}\text { MB } \\
\text { MG } \\
\text { DR } 81\end{array}$ & $\begin{array}{c}7.63 \\
7.58 \\
0.036\end{array}$ & $\begin{array}{l}-2.72 \\
-5.37 \\
8.77\end{array}$ & & & \\
\hline
\end{tabular}

The entropy of the overall process is a sum of the entropy of ion exchange which occurs at the solid-liquid interface and the binding forces of dye molecule with the adsorbent. In this experiment, ion-exchange might 
not be the main mechanism, because the enthalpy changes for ion-exchange reactions are usually smaller than $8.4 \mathrm{~kJ} / \mathrm{mol}$ as suggested by Lyubchik et $a l^{28}$ whereas the calculated value of enthalpies for different adsorbents in the present study are higher than this.

\section{CONCLUSION}

From the present research, it is estimated that NB and ANB are better adsorbents than PP and APP for basic dyes, Methylene Blue and Malachite Green. Higher adsorption of ANB might be due to the functional group $(\mathrm{OH}$, carboxylic and esters group) built upon the sorbent surface after sulphuric acid treatment as previously publicized with the help of FTIR study. Also, the rough surface of neem bark adsorbent added the surface area for the acquisition of dye molecules. For removal of Direct Red 81, formaldehyde-treated potato peel (PP) emerged out as the superior adsorbent than the rest of the three adsorbents NB, APP and ANB studied. Here both the formaldehyde-treated adsorbents PP and NB worked better than the acid-treated adsorbents APP and ANB. The smooth surface area of PP and a variety of functional groups played an important role in the sorption of DR 81 dye.

The smooth surface properties of potato peel supported monolayer adsorption widely whereas neem bark favored the heterogeneous sorption process due to the rough surface appearance as claimed through SEM images previously. The pseudo-second-order kinetic model is the best-fitted model for governing the rate of reaction with all types of adsorbents. The process is estimated to be exothermic and spontaneous which accomplished with a decrease in the degree of freedom. All the adsorbents favored Freundlich and Temkin's model isotherm compare to the Langmuir model isotherm. The process examined is found to be exothermic but non-spontaneous in the case of DR 81 dye. Finally from the study, it is concluded that the efficiency of adsorption is highly dependent on the parent material (sorbent), the type of component to be removed (sorbet) and the type of chemical treatment to be given. Here from the study, it is estimated that ANB worked remarkably for cationic dyes while PP worked efficiently for anionic dye.

\section{ACKNOWLEDGEMENT}

The corresponding author is thankful to the Department of Environmental Engineering DTU, Delhi, and DCRUST, Murthal for the all-time support and Cooperation.

\section{REFERENCES}

1. CO' Neill, F.R. Hawkes, D.L. Hawkes, N. Lourenco, H.M. Pinheiro, W. Delee, Journal of Chemical Technology Biotechnology, 74(11), 1009(1999), DOI:10.1002/(SICI)10974660(199911)74:11<1009::AID-JCTB153>3.0.CO;2-N

2. Z.G. Hu, J. Zhang, W.L. Chan, Y.S. Szeto, Polymer, 47, 5838(2006), DOI:10.1016/j.polymer.2006.05.071

3. J. Liu, M. Crapper, G.L. McConnachie, Water Resource, 38, 875(2003), DOI:10.1016/j.watres.2003.10.014

4. S. Li-Q, Z. K. Xu, Z. M. Liu, Y. Y Xu, Journal of Membrane Science, 218, 279(2003), DOI:10.1016/S0376-7388(03)00186-8

5. S. H. Lin, A. L. Chen, Water Research, 31, 868(1997), DOI:10.1016/S0043-1354(96)00318-1

6. I. Koyuncu, Journal of Chemical Technology and Biotechnology, 78(12), 1219(2003), DOI: $10.1002 /$ jctb.924

7. Jayant Gandhi, Rajesh Dangi and Shipra Bhardwaj, Rasayan Journal of Chemistry, 1(3), 567(2008)

8. F.H. Hussein, T.A. Abass, International Journal of Chemical Science, 8(3), 1353(2010)

9. S. Sadrghayeni, P. Beatson, R. Schneider, A. Fane, Desalination, 116, 65(1998), DOI:10.1016/S00119164(98)00058-7

10. E. H. Snider, J. J. Porter, Journal of Water Pollution Control Federation, 46, 886(1994)

11. I. M. Beydilli, S. G. Pavlostathis, W.C. Tincher, Water Environment Research, 72, 698(2000) DOI: $10.2175 / 106143000 X 138319$

12. P. Venkateswaran, K. Palanivelu, Journal of Hazardous Materials ,131(1-3),146(2006), DOI:10.1016/j.jhazmat.2005.09.025 
13. H. Revathi, Ashlin Xavier, M. Dinesh Kumar, T.Saranya, A. Kaviyarasu, T. Murugan, Rasayan Journal of Chemistry, 12(2), 719(2019), DOI:10.31788/RJC.2019.1225094

14. G. Crini, (2006), Bioresource Technology, 97, 1061(2006), DOI:10.1016/j.biortech.2005.05.001

15. V. K. Garg, R. Gupta, A. B. Yadav, R. Kumar, Bioresource Technology, 89, 121(2003), DOI: 10.1016/S0960-8524(03)00058-0

16. S. P. Raghuvanshi, R. Singh, C. P. Kaushik, Applied Ecology and Environmental Research, 2(2), 35(2004), DOI: 10.15666/aeer/03035043

17. T. Parvathi, S. Maruthvanan, S. C. Prakash, C.V. Koushik, Indian Journal of Science and Technology, 3(3), 290(2010)

18. Z. Q. Zhang, Y. P. Zhang, Journal of Northwest Sci-Tech University of Agriculture and Forestry, 26(2), 94(1998)

19. D. P. Tiwari, S. K. Singh, N. Sharma, Applied Water Science, 581(2015), DOI:10.1007/s13201-0140171-0

20. C. Namasivayam, N. Muniasamy, K. Gayathri, M. Rani, K. Ranganathan, Bioresource Technology, 57, 37(1996), DOI: 10.1016/0960-8524(96)00044-2

21. L. S. Tan, K. Jain, C. A. Rozaini, Journal of Applied Sciences in Environmental Sanitation, 5(3), 283(2010)

22. K. A. Krishnan, T. S. Anirudhan, Water Soil Air, 29(2), 147(2003), DOI:10.4314/wsa.v29i2.4849

23. R. Mohammad Samarghandi, M. Zarrabi, N. Mohammad Sepehr, A. Amrane, G. H. Safari, S. Bashiri, Iranian Journal of Environmental Health Science \& Engineering, 9, 9(2012), DOI:10.1186/1735-27469-9

24. O. Gulnaz, A. Kaya, Journal of Hazardous Materials, 134, 190(2006), DOI:10.1016/j.jhazmat.2005.10.050

25. A. P. Flavio, A. C. Mazzocato, Y. Gushikem, Bioresource Technology, 99, 3162(2008), DOI:10.1016/j.biortech.2007.05.067

26. F. Ferrero, Journal of Hazardous Materials, 142, 144(2007), DOI:10.1016/j.jhazmat.2006.07.072

27. S. T. Akar, A. S. Özcan, Desalination, 249, 757(2009), DOI:10.1016/j.desal.2008.09.012

28. S. I. Lyubchik, A. I. Lyubchik, O. L. Galushko, Colloids Surface A, 242(1-3), 151(2004) DOI:10.1016/j.colsurfa.2004.04.066

29. S. Senthikumar, P. R. Varatharajan, K. Porkodi, C. V. Subburaam, Colloid Interface Science, 284(1), 78(2005), DOI: 10.1016/j.jcis.2004.09.027

30. N. T. Abdel - Ghani, M. Hefny, G. A. F. El - Chaghaby, International Journal of Environment Science and Technology, 4(1), 67(2007), DOI:10.1007/BF03325963

31. K.W. Kolasniski, (2001), Surface Science, Wiley, Chister, UK.

32. M. Hema, S. Arivoli, Journal of Applied Science and Environmental Management, 12(1), 43(2008) DOI: $10.4314 /$ jasem.v12i1.55568

33. Y. C. Sharma, B. Singh, Uma, The Open Environmental Pollution and Toxicology Journal, 1, 74(2009)

34. M. M. Heravi, A. Kodabande, M. R. Bozorgmehr, T. Ardalan, P. Ardalan, Journal of Chemical Health Risks, 2(4), 37(2012)

35. T. A. Khan, S. Dahiya, I. Ali, Gazi University Journal of Science, 25(1), 59(2012)

36. Neetu Sharma, D.P. Tiwari, S. K. Singh, Rasayan Journal of Chemistry, 7(4), 399(2014)

37. Y. A. O"ktem, S. G. P Soylu, N. Aytan, Journal of Scientific and Industrial Research, 71,817(2012)

38. R. Srivastva, D. C. Rupainwar, Desalination and Water Treatment, 24, 74(2010) DOI: $10.5004 /$ dwt.2010.1195

39. R. Srivastava, D. C. Rupainwar, Indian Journal of Chemical Technology, 18, 67(2011)

40. B. von Oepen, W. Kordel, W. Klein, Chemosphere, 27(1/2), 285(1991), DOI:10.1016/00456535(91)90318-8

[RJC-5405/2019] 